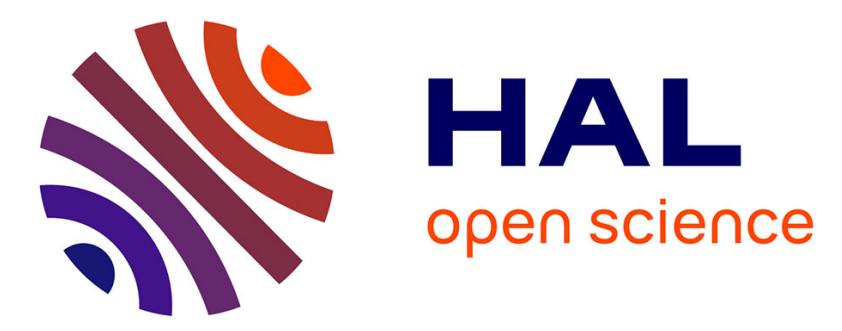

\title{
Alternative pathways of dehydroascorbic acid degradation in vitro and in plant cell cultures: novel insights into vitamin $\mathrm{C}$ catabolism
}

\author{
Harriet Tempé Parsons, Tayyaba Yasmin, Stephen C. Fry
}

\section{To cite this version:}

Harriet Tempé Parsons, Tayyaba Yasmin, Stephen C. Fry. Alternative pathways of dehydroascorbic acid degradation in vitro and in plant cell cultures: novel insights into vitamin $\mathrm{C}$ catabolism. Biochemical Journal, 2011, 440 (3), pp.375-383. 10.1042/BJ20110939 . hal-00658156

\section{HAL Id: hal-00658156 https://hal.science/hal-00658156}

Submitted on 10 Jan 2012

HAL is a multi-disciplinary open access archive for the deposit and dissemination of scientific research documents, whether they are published or not. The documents may come from teaching and research institutions in France or abroad, or from public or private research centers.
L'archive ouverte pluridisciplinaire HAL, est destinée au dépôt et à la diffusion de documents scientifiques de niveau recherche, publiés ou non, émanant des établissements d'enseignement et de recherche français ou étrangers, des laboratoires publics ou privés. 
REFERENCE: BJ2011/0939

TYPE: Full Paper

former TITLE: Oxidative and hydrolytic pathways of dehydroascorbic acid breakdown in vitro and in plant cell cultures are steered by ROS status, ascorbate concentration and apoplastic enzymes

AUTHORS: Harriet Tempé Parsons, Tayyaba Yasmin, Stephen C. Fry

\title{
Alternative pathways of dehydroascorbic acid degradation in vitro and in plant cell cultures: novel insights into vitamin $\mathrm{C}$ catabolism
}

\author{
Harriet T. PARSONS ${ }^{1}$, Tayyaba YASMIN ${ }^{2}$ and Stephen C. FRY ${ }^{3}$ \\ The Edinburgh Cell Wall Group, Institute of Molecular Plant Sciences, \\ School of Biological Sciences, The University of Edinburgh, The King's \\ Buildings, Edinburgh EH9 зЈH, U.K.
}

\footnotetext{
${ }^{1}$ Current address: Joint BioEnergy Research Institute, Lawrence Berkeley National Laboratories, 1 Cyclotron Road, Berkeley 94720, California, USA.

2 Current address: Department of Biosciences, COMSATS Institute of Information Technology, Islamabad, Pakistan

3 To whom correspondence should be addressed (emailS.Fry@Ed.Ac.UK). Tel 01316505320 - Fax 01316505392.
} 


\title{
SYNOPSIS
}

L-Ascorbate catabolism involves reversible oxidation to dehydroascorbic acid (DHA), then irreversible oxidation or hydrolysis. The precursor-product relationships and the identity of several major DHA breakdown products remained unclear. In the presence of added $\mathrm{H}_{2} \mathrm{O}_{2}$, DHA underwent little hydrolysis to 2,3-diketogulonate (DKG). Instead it yielded oxalyl-threonate $\left(\mathrm{OxT}^{2-}\right)$, cyclic-oxalyl-threonate $\left(\mathrm{cOxT}^{-}\right)$and free oxalate $(\sim 6: 1: 1)$, essentially simultaneously, suggesting that all three product classes independently arose from one reactive intermediate, proposed to be cyclic-2,3-O-oxalyl-Lthreonolactone. Only with plant apoplastic esterases present were the esters significant precursors of free oxalate. Without added $\mathrm{H}_{2} \mathrm{O}_{2}$, DHA was slowly hydrolysed to DKG. Downstream of DKG was a singly ionised dicarboxy compound (suggested to be 2-carboxy-L-xylonolactone plus 2-carboxy-Llyxonolactone), which reversibly de-lactonised to a dianionic carboxypentonate. Formation of these lactones and acid was minimised by the presence of residual unreacted ascorbate. In vivo, the putative 2 carboxy-L-pentonolactones were relatively stable. We propose that DHA is a branch-point in ascorbate catabolism, being either oxidised to oxalate and its esters or hydrolysed to DKG and downstream carboxypentonates. The oxidation:hydrolysis ratio is governed by reactive oxygen species status. In vivo, oxalyl esters are enzymatically hydrolysed, but the carboxypentonates are stable. The biological roles of these ascorbate metabolites invite future exploration.

Short (page heading) title: Dehydroascorbic acid catabolism

\section{Key words}

carboxy-L-xylonic acid

diketogulonic acid

oxalyl threonate

hydrogen peroxide

oxalyl esterase

vitamin $\mathrm{C}$

\begin{abstract}
Abbreviations used: A, dehydroascorbic acid (in equations); $\mathrm{AH}_{2}$, ascorbic acid (in equations); cOxT, cyclic oxalyl threonate; DHA, dehydroascorbic acid; DKG, 2,3-diketogulonate; HPLC, high-pressure liquid chromatography; HVPE, high-voltage paper electrophoresis; $m_{\mathrm{OG}}$, electrophoretic mobility relative to that of orange $\mathrm{G}\left(m_{\mathrm{OG}}=1.0\right)$ and glucose

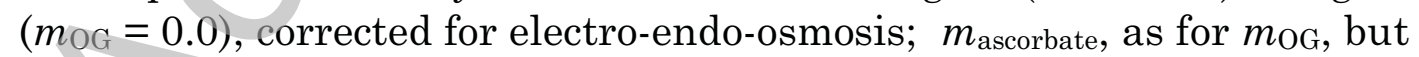
relative to ascorbate; OG, orange G; OxA, oxalate; OxT, oxalyl threonate; ROS, reactive oxygen species.
\end{abstract}




\section{INTRODUCTION}

L-Ascorbate fulfils multiple essential roles in both plants and animals. It has a well-established intraprotoplasmic role as antioxidant, e.g. in chloroplasts [1,2]. In the apoplast (aqueous solution permeating the cell wall) of plants, it is the principal redox buffer, where it regulates responses to the extracellular environment [3-6]. It is implicated in the defence of plants against pathogens [7] and in the control of plant growth and development [8,9], including flowering, senescence [10] and root development [11]. Besides serving as an anti-oxidant [12,13], it may also act as a pro-oxidant that generates hydroxyl radicals in the apoplast $[14,15]$ and thereby causes the non-enzymatic scission of neighbouring polysaccharides $[14,16,17]$. Such scission may contribute to the cell-wall loosening required for fruit softening $[18,19]$ and cell expansion [20,21]. Interesting biological roles in the apoplast for ascorbate's primary oxidation product, dehydroascorbate (DHA), have also been proposed [22]. Therefore, ascorbate and DHA metabolism in plants is highly significant; however, many questions concerning their catabolic pathways and the identity of major degradation products remain open.

There is generally accepted to be one predominant pathway by which ascorbate is synthesised in Arabidopsis [23-25]. Intraprotoplasmically, it is recycled (reversibly oxidised to DHA) by the ascorbate-glutathione cycle [26]. DHA is best represented as a bicyclic structure (Fig. 1, top left) [27]. It can be further broken down in vivo via reactions that are widely accepted to be irreversible under physiological conditions [28], thus escaping the ascorbate-glutathione cycle.

Several pathways exist for irreversible ascorbate or DHA catabolism in plants, some being taxonomically restricted. Plants in the Vitaceae, e.g. grapes, accumulate L-threarate (= tartrate) as an end-product of enzymatic ascorbate catabolism via L-idonate [29,30]. Grapes also accumulate oxalate (OxA), which is synthesised from ascorbate [31]. Ascorbate also acts as a precursor to threarate in Pelargonium crispum, but here L-threonate (ThrO), not L-idonate, acts as an intermediate and OxA is a by-product $[30,32]$.

ThrO plus OxA are well-established in-vitro end-products of ascorbate oxidation [33,34]. More recently, Green and Fry [35] described a catabolic pathway by which OxA and ThrO are produced from DHA by oxidative cleavage of the C-2-C-3 bond followed by several further steps. This pathway was proposed to proceed via the novel metabolites cyclic oxalyl Lthreonate (cOxT) and oxalyl L-threonate $(\mathrm{OxT})$. The core of the pathway (dashed arrows in Fig. 1) was proposed to be linear: DHA - (oxidation) $\rightarrow$ $2,3-\mathrm{cOx}$ - (acyl migration $) \rightarrow 3,4-\mathrm{cOxT}-($ hydrolysis $) \rightarrow 4-\mathrm{OxT}-$ (hydrolysis) $\rightarrow$ 4-OxA + ThrO [35]. Isbell and Frush [34] had hypothesised 2OxT as an intermediate, but had not detected it experimentally. The proposed pathway represents a means by which OxA and ThrO can be produced from ascorbate and which is likely to common to all plant species since all the steps can occur non-enzymatically in vitro. Although these 
reactions can occur non-enzymatically, some of the steps were catalysed by enzymes [35], especially the oxidation of ascorbate to DHA and the hydrolysis of OxT to OxA + ThrO, but probably also the oxidation of DHA and hydrolysis of cOxT to OxT.

Several important uncertainties remain concerning the sequence of reactions during DHA oxidation and the identity of some of the intermediary metabolites. For example, we had assumed that all OxA and ThrO was produced via the linear pathway $\mathrm{DHA} \rightarrow \mathrm{cOxT} \rightarrow \mathrm{OxT} \rightarrow \mathrm{OxA}+$ ThrO. An alternative to this assumption is the possibility that some of the OxA is formed from 2,3-diketo-L-gulonate (DKG), the hydrolysis product of DHA [36]. We have therefore now re-tested the possible intermediary role of DKG. Another alternative is that OxT, or even free OxA + ThrO, is formed from DHA directly, without the intermediacy of a cyclic ester; we have therefore now also re-tested this by more detailed time-course studies.

Green and Fry [35] proposed that DKG yielded two mutually interconvertible, but unidentified, $\mathrm{C}_{6}$ products: $\mathbf{C}$ and $\mathbf{E}$. Simpson and Ortwerth [37] describe oxidative and non-oxidative in-vitro breakdown pathways of DKG yielding OxA in both pathways and ThrO during oxidative breakdown, but their results did not suggest possible identities for $\mathbf{C}$ or $\mathbf{E}$. We have therefore further explored the conditions under which $\mathbf{C}$ and/or $\mathbf{E}$ are produced, and investigated for the first time the fate of $\mathbf{C} / \mathbf{E}$ in vivo.

In the present study we monitored the oxidative and/or hydrolytic breakdown of ascorbate, DHA and DKG in aerated aqueous solutions under physiological conditions of temperature and apoplastic $\mathrm{pH}$, and with three severities of oxidation:

- 'strongly' oxidising conditions, with added $\mathrm{H}_{2} \mathrm{O}_{2}$;

- 'moderately' oxidising conditions, with (at least initially) a supply of an agent capable of making endogenous $\mathrm{H}_{2} \mathrm{O}_{2}$ from dissolved $\mathrm{O}_{2}$ such as ascorbate $\left(\mathrm{AH}_{2}+\mathrm{O}_{2} \rightarrow \mathrm{A}+\mathrm{H}_{2} \mathrm{O}_{2}\right)$ or DHA (which can also slowly yield sufficient $\mathrm{H}_{2} \mathrm{O}_{2}$ to support Fenton reactions [14]); and

- 'weakly' oxidising conditions (e.g. DKG $+\mathrm{O}_{2}$ ) with no obvious means of forming reactive oxygen species (ROS).

Products were analysed by high-voltage paper electrophoresis (HVPE) and HPLC. HVPE has proved particularly valuable in kinetic analyses of low$\mathrm{M}_{\mathrm{r}}$, unstable, radiolabelled organic acids. We have now further explored both principal forks of DHA degradation, under various conditions mimicking the plant apoplast in various respects. We compared strongly, moderately and weakly oxidising conditions, at various physiologically relevant $\mathrm{pH}$ values, and in the presence or absence of culture medium, enzymes and cells, and with low or high ascorbate concentrations. We did not attempt to model the fate of plastidic or cytosolic DHA, which may be rapidly salvaged back to ascorbate in the reducing enviromnent of the protoplasm compared with the apoplast. Previously unidentified intermediates were isolated, further characterised, and tested for their own 
susceptibility to oxidation and hydrolysis. In this way in-vitro branched pathways of DHA degradation have been compiled which can be used as comparative models for the in-vivo fate of these compounds. In addition, during attempts to scale up the preparation of ascorbate metabolites we noticed that some of them were only poorly generated at higher substrate concentraions; we have therefore also explored the effect of ascorbate concentration on the pattern of oxidation products generated.

\section{MATERIALS AND METHODS}

\section{Chemicals}

Ascorbic acid, DHA, $\mathrm{H}_{2} \mathrm{O}_{2}$ and catalase were from Sigma Chemical Co. Solid L-[1- $\left.{ }^{14} \mathrm{C}\right]$ ascorbic acid $(0.52$ or $0.407 \mathrm{MBq} / \mu \mathrm{mol})$ from $\mathrm{GE}$ Healthcare was dissolved in water, aliquotted and stored at $-80^{\circ} \mathrm{C}$ until required.

\section{Oxidation of ascorbate under strongly oxidising conditions}

All incubations were performed at $20^{\circ} \mathrm{C}$ in open tubes (thus with dissolved $\mathrm{O}_{2}$ ). For ascorbate oxidation experiments under strongly oxidising conditions, the reaction mixture $(500 \mu \mathrm{l})$ contained $10-20 \mathrm{mM}$ ascorbic acid (including $16 \mathrm{kBq} \mathrm{L}-\left[1-{ }^{14} \mathrm{C}\right]$ ascorbate), $80 \mathrm{mM}$ pyridinium acetate buffer, $\mathrm{pH}$ 6.0 (i.e., $80 \mathrm{mM}$ pyridine, $\mathrm{pH}$ adjusted to 6.0 with acetic acid), and $2 \mathrm{~mol}$ eq $\mathrm{H}_{2} \mathrm{O}_{2}$ (added last). With all reaction mixtures containing exogenous $\mathrm{H}_{2} \mathrm{O}_{2}$, $20-\mu \mathrm{l}$ aliquots were taken at intervals, treated with $1-4 \mathrm{U}$ catalase for $\sim 10 \mathrm{~s}$, frozen in liquid $\mathrm{N}_{2}$ and subjected to HVPE.

\section{Oxidation of ascorbate under moderately oxidising conditions}

For ascorbate degradation experiments under moderately oxidising conditions in the absence of deliberately added metal ions, the reaction mixture contained carrier-free L-[1-14C] ascorbic acid $(25 \mathrm{kBq} / \mathrm{ml} ; 48 \mu \mathrm{M})$ in water $(\mathrm{pH} \approx 4.4)$, and samples were frozen at the time-points indicated, then analysed by HVPE. Reaction-mixtures were aerated by gentle shaking, but no exogenous $\mathrm{H}_{2} \mathrm{O}_{2}$ was added. For corresponding experiments with cultures and/or media, carrier-free L-[1-14C] ascorbic acid was used at $22.5 \mathrm{kBq} / \mathrm{ml}$ $(360 \mu \mathrm{M})$ and the medium was buffered with $5 \mathrm{mM}$ Mes $\left(\mathrm{Na}^{+}, \mathrm{pH} 6.0\right)$.

\section{Fate of compounds $\mathrm{C}$ and $\mathrm{E}$ in vivo and in vitro}

${ }^{14} \mathrm{C}$-Labelled compound $\mathbf{C}$ was freshly eluted from an electrophoretogram (similar to that shown in Fig. 5b) and then tracer levels of it were incubated with medium and/or cultured plant cells. 


\section{Alkaline hydrolysis of compound C}

Additional tracer-level aliquots of ${ }^{14} \mathrm{C}$-labelled compound $\mathbf{C}$ were alkalihydrolysed in $0.1 \mathrm{M} \mathrm{NaOH}$ at $20^{\circ} \mathrm{C}$ for $2 \mathrm{~h}$ and then adjusted to $\mathrm{pH} 4.7$ with acetic acid. Controls were treated with the same amounts of acetic acid and $\mathrm{NaOH}$ but in reverse order so that the sample was never at an alkaline $\mathrm{pH}$. Radioactive products were analysed by HVPE.

\section{HVPE}

Samples were dried on Whatman No. 1 paper and electrophoresed in a volatile buffer at pH 6.5 (acetic acid-pyridine-water, 1:33:300 by volume, containing $5 \mathrm{mM}$ EDTA), usually at $3.0 \mathrm{kV}$ for $40 \mathrm{~min}$ [38]. The papers were cooled to $20-25^{\circ} \mathrm{C}$ with toluene during the run. Orange $\mathrm{G}(\mathrm{OG})$ was used as an internal reference marker and/or was loaded between samples. Nonradioactive compounds were stained with $\mathrm{AgNO}_{3}$ [39]. ${ }^{14} \mathrm{C}$-Labelled compounds were detected by autoradiography and quantified by scintillation counting. Samples required for further analysis were isolated by elution from electrophoretograms in water.

\section{Rosa cell-suspension cultures}

Rosa sp. ('Paul's Scarlet' rose) cell-suspension cultures were maintained as described [35] and subcultured fortnightly. Transition metal ions in the fresh medium ( $\mathrm{pH}$ 6.0) were $20 \mu \mathrm{M} \mathrm{Fe}^{3+}, 4.5 \mu \mathrm{M} \mathrm{Mn}^{2+}, 0.08 \mu \mathrm{M} \mathrm{Cu}^{2+}$ and $0.04 \mu \mathrm{M} \mathrm{Co}^{2+}$. These are likely to be higher than the free concentrations normally present in the apoplast; however, for the oxidation/hydrolysis experiments described here, 4-to 5-day-old cultures were used, in which the majority of the transition metal cations would have been taken up by the cells and/or bound to wall polymers. Cultures were passed through muslin and only the small cell-aggregates (harvested in the filtrate) were used. Spent medium was obtained by filtration through a fine nylon mesh or a glass-wool plug that was impenetrable to cells; when indicated, enzymes in the filtrate were denatured at $100^{\circ} \mathrm{C}$ for $15 \mathrm{~min}$.

\section{Detection of radioactivity}

Radioactive compounds on paper electrophoretograms were detected by autoradiography on Kodak BioMax MR-1 film. In some cases, the radioactive areas of the paper were cut out and ${ }^{14} \mathrm{C}$ was quantified by scintillation counting in 'OptiScint HighSafe'. 


\section{RESULTS AND DISCUSSION}

\section{Pathway initiation: oxidation of ascorbate to DHA}

Both branches of apoplastic ascorbate degradation begin with its oxidation to DHA. Under strongly oxidising conditions at $\mathrm{pH}$ 6.0, 2 molar equivalents (mol eq) of $\mathrm{H}_{2} \mathrm{O}_{2}$ rapidly oxidised $10 \mathrm{mM}$ [1-14C] ascorbate, initially to neutral DHA (Fig. 2a), the ascorbate being consumed with a half-life of $\sim 50 \mathrm{~min}$ (Fig. 2b). Over the 0-30-min period of observation, with average concentrations of $\sim 6 \mathrm{mM}$ ascorbate and $\sim 15 \mathrm{mM} \mathrm{H}_{2} \mathrm{O}_{2}$ present, we estimate the rate constant for the ascorbate $+\mathrm{H}_{2} \mathrm{O}_{2}$ reaction to be $1.6 \times 10^{-2} \mathrm{M}^{-1} \mathrm{~s}^{-1}$.

This experiment was conducted four times with qualitatively similar results; a representative electrophoretogtam is shown in Fig. $2 \mathrm{a}$ and this specific electrophoretogram is quantified in Fig. $2 b-d$. In contrast, under weakly oxidising conditions (with $\mathrm{O}_{2}$ but in the absence of added $\mathrm{H}_{2} \mathrm{O}_{2}$ and transition metal ions), $10 \mathrm{mM}$ ascorbate had a half-life of $\sim 8 \mathrm{~h}$ (Fig. 3).

\section{The DHA oxidation branch}

Non-enzymatic degradation of ascorbate-derived DHA under strongly
oxidising conditions

Theoretically, $1 \mathrm{~mol}$ eq of $\mathrm{H}_{2} \mathrm{O}_{2}$ is sufficient for the complete oxidation of ascorbate to DHA $\left(\mathrm{AH}_{2}+\mathrm{H}_{2} \mathrm{O}_{2} \rightarrow \mathrm{A}+2 \mathrm{H}_{2} \mathrm{O}\right)$. A second mol equiv of $\mathrm{H}_{2} \mathrm{O}_{2}$ enabled the [ $\left.{ }^{14} \mathrm{C}\right] \mathrm{DHA}$ to be further oxidised, after the first $30-60 \mathrm{~min}$, to products with the oxidation state of $\mathrm{OxA}+\mathrm{ThrO}$ (Fig. 2b). Major ${ }^{14} \mathrm{C}$ labelled products co-electrophoresed with cOxT, OxT and free OxA (Fig. 2a), and non-radioactive free $\mathrm{ThrO}$ (data not shown). Similar products were obtained with reaction mixtures buffered at $\mathrm{pH} 4,5$ and 7 (data not shown). DKG was a minor component, and compounds $\mathbf{C}$ and $\mathbf{E}$ were undetectable under these strongly oxidising conditions.

During the 5-60-min period of observation, when the average DHA and $\mathrm{H}_{2} \mathrm{O}_{2}$ concentrations were $\sim 2.5$ and $10 \mathrm{mM}$ respectively, rate constants for the $\left(\mathrm{DHA}+\mathrm{H}_{2} \mathrm{O}_{2} \rightarrow\right.$ product) reactions are estimated at $3.4 \times 10^{-2}, 4.8 \times$ $10^{-3}$, and $3.5 \times 10^{-3} \mathrm{M}^{-1} \mathrm{~s}^{-1}$, for OxT, cOxT and OxA respectively (Fig. 2b,c).

\section{Essentially simultaneous generation of cOxT, OxT and OxA during DHA oxidation}

It was earlier proposed [35] that cOxT was an obligatory precursor of OxT. However, contradicting this hypothesis, we observed that OxT and cOxT accumulated simultaneously (Fig. 2 b,c). Their ratio remained almost constant ( $6: 1)$ for the first $60 \mathrm{~min}$, increasing only slightly between 60 and $480 \mathrm{~min}$ as the cyclic ester was slowly hydrolysed to OxT (Fig. 2d). The rate of total oxalyl ester accumulation $(\mathrm{cOxT}+\mathrm{OxT})$ varied in proportion to the concentration of their presumed common precursor, DHA, decreasing after 
the first 60-120 min. However, the rate of OxT production did not vary in proportion to the concentration of $\mathrm{cOxT}$, which plateaued at 240-480 min (Fig. 2b). Thus cOxT is not an obligatory precursor of OxT, and both types of ester are formed essentially simultaneously during the oxidation of DHA.

Like $\left[{ }^{14} \mathrm{C}\right] \mathrm{OxT}$, free $\left[{ }^{14} \mathrm{C}\right] \mathrm{OxA}$ was also produced much more rapidly during the first 120 min than later. This indicates that only a minority of the OxA arose by hydrolysis of OxT. If OxA did arise mainly from esters, its rate of accumulation would peak at $480 \mathrm{~min}$, when the ester concentration was highest. Furthermore, the OxA:OxT ratio decreased slightly between 16 and $480 \mathrm{~min}$, whereas an increase would have been expected if much ester hydrolysis were occurring. The pattern of free $\left[{ }^{14} \mathrm{C}\right] \mathrm{OxA}$ formation suggests that most of it arose from a substance whose concentration, like that of DHA but unlike that of OxT, decreased during the incubation.

We conclude that under non-enzymatic conditions cOxT is not an obligatory precursor of $\mathrm{OxT}$, and $\mathrm{OxT}$ is not an obligatory precursor of free OxA during the $\mathrm{H}_{2} \mathrm{O}_{2}$-driven oxidation of DHA. The data suggest that $\mathrm{H}_{2} \mathrm{O}_{2}$ oxidises DHA to a reactive intermediate (I) that almost simultaneously generates three alternative end-products - $\mathrm{OxT}, \mathrm{cOxT}$ and free $\mathrm{OxA}$ in a ratio of $\sim 6: 1: 1$ (Fig. 2d). We propose that (I) is cyclic 2,3-O-oxalyl L-threonolactone, formed when bicyclic DHA reacts with $\mathrm{H}_{2} \mathrm{O}_{2}$, oxidatively cleaving the C-2-C3 bond such that the original carbons 1 and 2 become a cyclic oxalyl ester group, and the hemiketal furanose ring becomes a $\gamma$-lactone ring (Fig. 1). We propose that (I) is highly unstable in aqueous solution at $\mathrm{pH} 4-7$, rapidly undergoing hydrolysis at any of the bonds labelled $\mathrm{a}, \mathrm{b}$ and $\mathrm{c}$ in Fig. 1. To account for the observed ratio of end-products formed under the conditions used in Fig. 2, we assume that the first hydrolysis reaction of (I) had a 1/8 chance of targeting the lactone ring (bond c) to produce the relatively stable cOxT, or a $7 / 8$ chance of targeting one of the two oxalyl ester bonds (a or b; a was arbitrarily chosen for Fig. 1) to produce 2 - or 3-O-oxalyl Lthreonolactone (II). Intermediate (II) would itself be highly unstable, quickly undergoing hydrolysis either at bond $\mathrm{c}(6 / 7$ chance) to yield the relatively stable OxT, or at the remaining oxalyl ester linkage (a or b; $1 / 7$ chance) to yield $\mathrm{OxA}$ and threonolactone. Fig. 1 shows $3-\mathrm{OxT}$ as the first-formed product of (II), later converting to 4-OxT, the metabolite reported earlier [35]; we have indeed recently obtained evidence for rapid 3-OxT $\leftrightarrow 4$-OxT interconversion by acyl migration (data not shown). Later, most of the threonolactone itself would be hydrolysed to free ThrO. This interpretation would account for the 6:1:1 ratio (OxT : cOxT : OxA) observed among products stable enough to be isolated by HVPE.

After the rapid oxidation of DHA to form (almost simultaneously) cOxT, OxT and OxA, the subsequent inter-conversion of these products by hydrolysis (cOxT $\rightarrow$ OxT $\rightarrow$ OxA) was, in the absence of enzymes, much more gradual. When discussing Figs 4 and 5, we will show that when native apoplastic enzymes were present these hydrolysis steps did occur, indicating the presence of oxalyl esterase activities, which would operate in vivo. 


\section{The DHA oxidation branch}

Fate of ascorbate under moderately oxidising, non-enzymatic conditions: production of $D K G$

DHA in aqueous solution is reported to undergo rapid and essentially irreversible hydrolysis of the lactone ring to yield DKG [40], for example with a half-life of $21 \mathrm{~min}$ at $\mathrm{pH} 7$ and $27^{\circ} \mathrm{C}$ [41]. In contrast, at $\mathrm{pH} 2-4$, aqueous solutions of DHA are stable 'for days' [42]. In the experiment described in Fig. 2a, in the presence of exogenous $\mathrm{H}_{2} \mathrm{O}_{2}$, very little $\left[{ }^{14} \mathrm{C}\right] \mathrm{DKG}$ accumulated. This could be because the strongly oxidising conditions favoured the rapid oxidation of DHA to OxA and its esters over its gradual hydrolysis to DKG. Any downstream products normally formed via DKG would thus also have been under-represented in the experiments with exogenous $\mathrm{H}_{2} \mathrm{O}_{2}$.

Moderately oxidising conditions, more similar to those likely to occur in vivo, were achieved in aerated solutions, buffered at $\mathrm{pH} 4.4$, and containing some residual ascorbate and/or DHA. Under these (still non-enzymatic) conditions, cOxT, OxT and possibly free OxA were again formed simultaneously (Fig. 3) but much more slowly than in the presence of exogenous $\mathrm{H}_{2} \mathrm{O}_{2}$. At the later time points $(24-48 \mathrm{~h})$, concentrations of cOxT plateaued, but OxT continued to accumulate - as expected since a pool of its precursor, DHA, was maintained for this duration. The results indicate gradual oxidation of DHA simultaneously to cOxT, OxT and OxA, with the cOxT slowly hydrolysing to OxT during these lengthy incubations. Other products formed under these conditions included DKG, C and possibly $\mathbf{E}$ (Fig. 3).

In a further move towards in-vivo conditions, [14C]ascorbate was incubated in fresh culture medium (i.e., medium in which Rosa cells had never grown) or in heat-denatured culture filtrate (denatured spent medium). The fresh medium contains the transition metal ions $\mathrm{Fe}^{3+}$ and $\mathrm{Cu}^{2+}$, but in spent medium these ions would have been largely removed from free solution by the cells. Media were buffered at pH 6.0. [ $\left.{ }^{14} \mathrm{C}\right]$ Ascorbate in these media underwent reactions (Fig. 4a,d) similar to those reported in Fig. 3, except that yields of DKG were higher, probably because the higher $\mathrm{pH}$ promoted the hydrolysis of DHA's lactone ring. cOxT and OxT both accumulated simultaneously, and the cyclic ester plateaued as it turned over to the simple ester(s).

Under all conditions reported in Fig. 4, an additional, unidentified, product, designated compound $\mathbf{T}$, was also formed. If $\mathbf{T}$ has a net charge of approximately -1.0 at $\mathrm{pH} 6.5$, as is the case for most mono-carboxylic acids, then its low electrophoretic mobility relative to ascorbate $\left(m_{\text {ascorbate }}=0.88\right)$ indicates that it has a higher molecular weight than ascorbate and may thus be formed by condensation of the ascorbate skeleton to an additional compound present in the medium. 
Fate of ascorbate under moderately oxidising conditions in the presence of apoplastic enzymes

In similar culture medium with no exogenous $\mathrm{H}_{2} \mathrm{O}_{2}$ but in the presence of native apoplastic Rosa enzymes, both types of ester were again formed essentially simultaneously. However, they were unstable (Fig. 4b,c): the OxT appeared to be hydrolysed to OxA, which progressively accumulated, indicating oxalylesterase activity, although some OxT was maintained for the full $9 \mathrm{~h}$ of observation, suggesting that it continued to be replenished from DHA, whose pool was maintained. cOxT had fallen to undetectable concentrations by $6 \mathrm{~h}$, indicating that an esterase activity hydrolysed it to OxT faster than it could be replenished from DHA.

The results show that the products detectable during ascorbate oxidation depend on (a) the intensity of oxidation, with slow oxidation allowing time for cOxT to act appreciably as a precursor of OxT even in the absence of enzymes, and (b) the presence of apoplastic oxalylesterase activities, which strongly promote the turnover of cOxT to OxT and of OxT to OxA.

\section{Compounds $\mathrm{C}$ and $\mathrm{E}$ as downstream products of DKG in the absence of exogenous $\mathrm{H}_{2} \mathrm{O}_{2}$}

\section{Nature of compounds $\boldsymbol{C}$ and $\boldsymbol{E}$}

Compounds $\mathbf{C}$ and $\mathbf{E}$ are mutually interconvertible products of ascorbate degradation discovered under 'moderately oxidising' conditions [35]. C and E are $\mathrm{C}_{6}$ products of ascorbate, with respectively 1 and 2 negatively charged groups at $\mathrm{pH}$ 6.5; compound $\mathbf{C}$ is a lactonised form of $\mathbf{E}$ [35]. Conditions favouring their production were explored in more depth (Fig. 5). Their properties, including electrophoretic mobilities, suggested that $\mathbf{C}\left(m_{\mathrm{OG}}=\right.$ 1.38 at $\mathrm{pH} 6.5)$ and $\mathbf{E}\left(m_{\mathrm{OG}}=1.96\right.$ at $\left.\mathrm{pH} 6.5\right)$ were $\mathrm{C}_{6}$ compounds carrying one and two negative charges respectively; thus $\mathbf{C}$ was probably a reversibly lactonised form of $\mathbf{E}$. Most carboxy groups are almost fully ionised at pH 6.5. On electrophoresis at $\mathrm{pH} 2.0$, in contrast, the order of mobility was reversed: $\mathbf{C}\left(m_{\mathrm{OG}} \approx 0.65\right)$ had a higher negative charge:mass ratio than $\mathbf{E}\left(m_{\mathrm{OG}} \approx 0.41\right)$ [43], indicating that the single ionisable group of $\mathbf{C}$ has an unusually low $\mathrm{pK}_{\mathrm{a}}$. This behaviour is comparable to that of $\mathrm{cOxT}$ (with one ionisable group), which has a higher negative charge:mass ratio at $\mathrm{pH} 2.0\left(m_{\mathrm{OG}} \approx\right.$ 0.92 ) than $\mathrm{OxT}\left(m_{\mathrm{OG}} \approx 0.73\right)$, which has two, evidently more weakly, ionisable groups.

If we assume that both the anionic groups of $\mathbf{E}$ are $-\mathrm{COOH}$ groups, then $\mathbf{E}$ could theoretically be based on the straight-chain compound, adipic acid ( $\mathrm{HOOC}-\mathrm{CH}_{2}-\mathrm{CH}_{2}-\mathrm{CH}_{2}-\mathrm{CH}_{2}-\mathrm{COOH}$ ) with various $-\mathrm{OH}$ and $=\mathrm{O}$ groups attached; alternatively, it could be a branched structure based on, for example, $\mathrm{HO}-\mathrm{CH}_{2}-\mathrm{CH}_{2}-\mathrm{CH}_{2}-\mathrm{CH}-(\mathrm{COOH})_{2}$. An adipate-based structure seems unlikely since it would require non-enzymatic oxidation to have occurred at the relatively unreactive $-\mathrm{CH}_{2} \mathrm{OH}$ group (C-6 of DKG). On the other hand, a branched-chain structure would be produced by a benzilic acid 
rearrangement, such as occurs during saccharinic acid formation when a reducing sugar is treated with alkali [44]. A proposed reaction scheme compatible with all the observations is presented in Fig. 6, in which we suggest that $\mathbf{E}$ is 2-carboxy-L-threo-pentonate (= '2-carboxy-L-xylonate') and $\mathbf{C}$ is an epimeric mixture of the corresponding lactones (2-carboxy-Lxylonolactone and 2-carboxy-L-lyxonolactone). On this basis, compound $\mathbf{E}$ is nominally a derivative of 2-ethylmalonic acid, whose $p \mathrm{~K}_{\mathrm{a}}$ values are 3.0 and 5.8 (http://research.chem.psu.edu/brpgroup/pKa_compilation.pdf), which would account for its moderate electrophoretic mobility at $\mathrm{pH} 2.0$.

If this proposal for the origin and structure $\mathbf{C}$ and $\mathbf{E}$ is correct, then the formation of compound $\mathbf{C}$ from DKG is neither an oxidation nor a reduction. In agreement with our observations, it would therefore not be promoted by $\mathrm{H}_{2} \mathrm{O}_{2}$; indeed, the presence of added $\mathrm{H}_{2} \mathrm{O}_{2}$ would be predicted to decrease the $\mathrm{DKG} \rightarrow \mathbf{C}$ reaction by oxidising some of the DKG before the slow benzilic acid rearrangement was able to produce appreciable amounts of $\mathbf{C}$.

\section{Yield of $\boldsymbol{C}$ and $\boldsymbol{E}$ from ascorbate}

Ascorbate degradation gave widely varying yields of $\mathbf{C}$ and $\mathbf{E}$ in different experiments: undetectable (Fig. 2), traces (Fig. 3), moderate (Fig. 4) or high yields (Fig. 5c). If produced at all, $\mathbf{C}$ appeared before $\mathbf{E}$. Production of $\mathbf{C}$ and E from ascorbate was generally highest under conditions that favoured DKG accumulation, being greater under moderately oxidising conditions (i.e., with only endogenous $\mathrm{H}_{2} \mathrm{O}_{2}$; Figs 3,4 and 5) than under strongly oxidising conditions (Fig. 2) that quickly converted most of the DHA to oxalyl esters before it had had chance to be hydrolysed to DKG. These observations support the pathway ascorbate $\rightarrow$ DHA $\rightarrow$ DKG $\rightarrow \mathbf{C} \leftrightarrow \mathbf{E}$.

On incubation in culture medium under moderately oxidising conditions, dilute ascorbate $(0.1 \mathrm{mM})$ quickly gave a high yield of DKG (20-30\% within 2 h; Fig. 5a), which later diminished to near zero (Fig. 5c). Results were similar in this respect whether or not the medium contained active apoplastic enzymes. Simultaneously with this flux through DKG, compound $\mathbf{C}$ accumulated; compound $\mathbf{E}$ appeared later, with the total $(\mathbf{C}+\mathbf{E})$ reaching 20-25\% by $48 \mathrm{~h}$ (Fig. S2) and E eventually exceeding C. The presence of native culture filtrate (containing esterases) greatly reduced the levels of $\mathrm{OxT}$ and cOxT, as expected, without affecting the final yield of $\mathbf{E}$, indicating that the oxalyl esters were not precursors of $\mathbf{E}$. The production of $\mathbf{C}+\mathbf{E}$ coinciding with the production and consumption of DKG supports the idea that DKG was the precursor of $\mathbf{C}+\mathbf{E}$.

Ascorbate concentrations higher than $0.1 \mathrm{mM}$ led to a much lower percentage yield of $\mathbf{C}+\mathbf{E}$, and the DKG concentration steadily increased throughout the $48 \mathrm{~h}$ of observation, reaching 20-30\% (Fig. 5). These observations support the proposed pathway (ascorbate $\rightarrow$ DHA $\rightarrow$ DKG $\rightarrow \mathbf{C}$ $\leftrightarrow \mathbf{E}$ ), but suggest that the presence of some remaining unreacted ascorbate inhibits the DKG $\rightarrow \mathbf{C}$ step. 


\section{Fate of compounds $\boldsymbol{C}$ and $\boldsymbol{E}$ in vivo}

One reason for the variability in the yield of compounds $\mathbf{C}$ and $\mathbf{E}$ could be their possible degradation in vivo to unknown or undetectable products [5]. To explore this, we supplied electrophoretically purified ${ }^{14} \mathrm{C}$-labelled $\mathbf{C}$ at very low (tracer) concentrations to Rosa culture medium with or without cells and/or extracellular enzymes. The preparation of $\mathbf{C}$ initially contained only a small proportion of its de-lactonised form, $\mathbf{E}$ (Fig. $7 \mathrm{a}$ ). The ratio was almost unaffected by a treatment with cold dilute acid followed by neutralisation (Fig. 7b), but $\mathbf{C}$ was largely de-lactonised to $\mathbf{E}$ by cold dilute alkali followed by neutralisation (Fig. 7c). During incubation for 2 or $8 \mathrm{~h}$ in fresh culture medium (Fig. $7 \mathrm{~d}, \mathrm{~g}$ ), culture filtrate containing any native soluble extracellular enzymes (Fig. 7e,h), or whole Rosa culture still containing live cells (Fig. 7f,i), the ratio was if anything pushed towards the lactone $\mathbf{C}$ rather than the dianion $\mathbf{E}$. Thus, in vivo, compound $\mathbf{C}$ is a relatively stable end-product of apoplastic ascorbate/DHA/DKG metabolism, not readily metabolised further.

We conclude that the production of $\mathbf{C}$ and $\mathbf{E}$ in the apoplast in vivo will depend on several diverse factors including (a) ascorbate concentration, since residual ascorbate appeared to suppress $\mathbf{C}$ formation; and (b) $\mathrm{H}_{2} \mathrm{O}_{2}$, with highly oxidising conditions suppressing $\mathbf{C}$ formation by diverting the DKG to competing oxidative pathways.

\section{CONCLUSIONS}

In-vitro models produced during this study have shown two main pathways by which DHA is broken down: (a) oxidation to oxalyl esters, oxalate and threonate; and (b) hydrolysis to DKG, which can then be hydrolysed to carboxypentonates ( $\mathbf{C}$ and $\mathbf{E})$.

A comparison of in-vivo and in-vitro pathways highlighted the importance of esterases acting on oxalyl esters in the production of oxalate and threonate formed in vivo (Fig. 1). Conversely, there was little evidence for enzyme activity in the catabolism of DKG.

We previously suggested that apoplastic ascorbate concentrations vary in short-term pulses [45], with ascorbate being exported and DHA imported. In theory, such an export strategy could minimise the exposure of DHA to apoplastic conditions and therefore reduce the accumulation of $\mathrm{cOxT}, \mathrm{OxT}$, OxA, ThrO and carboxypentonates in the apoplast.

Although neither the DKG breakdown products nor the theoretical intermediates between DHA and its oxalate products have been identified conclusively, the use of HVPE has clarified the number of pathways stemming from DHA and DKG and the range of intermediates and endproducts involved. This has been an important step in consolidating previous data regarding DKG and DHA breakdown whilst adding new information on these pathways. HVPE has been an essential method in 
providing comprehensive analyses of reaction sequences at sufficient resolution for the capture of detailed information at even very early steps such as those in the DHA $\rightarrow$ oxalyl ester pathway. These in-vivo models provide an important reference point for future analysis of ascorbate metabolism in vivo and for an evaluation of the possible biological roles of ascorbate's diverse catabolites.

\section{ACKNOWLEDGEMENTS}

HTP thanks the UK Biotechnology and Biological Sciences Research Council for a studentship, during the tenure of which this work was done.

\section{REFERENCES}

1 Foyer, C. H. and Shigeoka, S. (2011) Understanding oxidative stress and antioxidant functions to enhance photosynthesis. Plant Physiol. 155, 93-100.

2 Noctor, G. (2006) Metabolic signaling in defence and stress: the central roles of soluble redox couples. Plant Cell Env. 29, 409-425.

3 Foyer, C. H. and Noctor, G. (2009) Redox regulation in photosynthetic organisms: signalling, acclimation and practical implications. Antiox. Redox Signal. 11, 861-905

4 Noctor, G. and Foyer, C. H. (1998) Ascorbate and glutathione: keeping active oxygen under control. Annu. Rev. Plant Physiol. Plant Mol. Biol. 49, 249-279

$5 \quad$ Banhegyi, G. and Loewus, F. A. (2004) Ascorbic acid catabolism: breakdown pathways in animals and plants. In Vitamin C, function and biochemistry in animals and plants (Asard H. , May J. M. , Smirnoff, N. eds. ), pp. 35-55. BIOS Scientific Publishers, London, UK

6 Mano, J., Hideg, E. and Asada, K. (2004) Ascorbate in thylakoid lumen functions as an alternative electron donor to photosystem II and photosystem I. Arch. Biochem. Biophys. 429, $71-80$

7 Pavet, V., Olmos, E., Kiddle, G., Mowla, S., Kumar, S. , Antoniw, J., Alvarez, M. E. and Foyer, C. H. (2005) Ascorbic acid deficiency activates cell death and disease resistance responses in Arabidopsis. Plant Physiol. 139, 1291-1303

8 Córdoba-Pedregosa, M. D., Cordoba, F. , Villalba, J. M. and González-Reyes, J. A. (2003) Differential distribution of ascorbic acid, peroxidase activity and hydrogen peroxide along the root axis in Allium cepa L. and its possible relationship with cell growth and differentiation. Protoplasma. 221, 57-65

9 Pastori, G. M. , Kiddle, G. , Antoniw, J. , Bernard, S. , Veljovic-Jovanovic, S. , Verrier, P. J., Noctor, G. and Foyer, C. H. (2003) Leaf vitamin C contents modulate plant defense transcripts and regulate genes that control development through hormone signaling. Plant Cell. 15, 939-951

10 Barth, C. , De Tullio, M. and Conklin, P. L. (2006) The role of ascorbic acid in the control of flowering time and the onset of senescence. J. Exp. Bot. 57, 1657-1665

11 Olmos, E. , Kiddle, G. , Pellny, T., Kumar, S. and Foyer, C. H. (2006) Modulation of plant morphology, root architecture and cell structure by low vitamin C in Arabidopsis thaliana. J. Exp. Bot. 57, 1645-1655 
12 Takahama, U. and Oniki, T. (1992) Regulation of peroxidase-dependent oxidation of phenolics in the apoplast of spinach leaves by ascorbate. Plant Cell Physiol. 33, 379-387

13 Sanmartin, M. , Drogoudi, P. D. , Lyons, T. , Pateraki, I. , Barnes, J. and Kanellis, A. K. (2003) Over-expression of ascorbate oxidase in the apoplast of transgenic tobacco results in altered ascorbate and glutathione redox states and increased sensitivity to ozone. Planta. 216, 918-928

14 Fry, S. C. (1998). Oxidative scission of plant cell wall polysaccharides by ascorbateinduced hydroxyl radicals. Biochem. J. 332, 507-515.

15 Kärkönen, A. and Fry, S. C. (2006) Effect of ascorbate and its oxidation-products on $\mathrm{H}_{2} \mathrm{O}_{2}$ production in cell-suspension cultures of Picea abies and in the absence of cells. J. Exp. Bot. 57, 1633-1644

16 Schweikert, C. , Liszkay, A. and Schopfer, P. (2000) Scission of polysaccharides by peroxidase-generated hydroxyl radicals. Phytochemistry 53, 565-570

17 Miller, J. G. and Fry,S. C. (2001). Characteristics of xyloglucan after attack by hydroxyl radicals. Carbohydr. Res. 332, 389-403

18 Fry, S. C. , Dumville, J. C. and Miller,J. G. (2001). Fingerprinting of polysaccharides attacked by hydroxyl radicals in vitro and in the cell walls of ripening pear fruit. Biochem. J. 357, 729-735

19 Dumville, J. C. and Fry, S. C. (2003) Solubilisation of tomato fruit pectins by ascorbate: a possible non-enzymic mechanism of fruit softening. Planta. 217, 951-961

20 Schopfer, P., Liszkay, A., Bechtold, M., Frahry, G. and Wagner, A. (2002)

Evidence that hydroxyl radicals mediate auxin-induced extension growth. Planta. 214, 821828.

21 Müller, K. , Linkies, A., Vreeburg, R. A. M., Fry, S. C. , Krieger-Liszkay, A. and Leubner-Metzger, G. (2009) In-vivo cell wall loosening by hydroxyl radicals during cress (Lepidium sativum L. ) seed germination and elongation growth. Plant Physiol. 150, 18551865

22 Lin, L. S. and Varner, J. E. (1991) Expression of ascorbic acid oxidase in zucchini squash (Cucurbita pepo L. ). Plant Physiol. 96, 159-165

23 Dowdle, J., Ishikawa, T., Gatzek, S. , Rolinski, S. and Smirnoff, N. (2007) Two genes in Arabidopsis thaliana encoding GDP-L-galactose phosphorylase are required for ascorbate biosynthesis and seedling viability. Plant J. 52, 673-689

24 Ishikawa, T. and Shigeoka, S. (2008) Recent advances in ascorbate biosynthesis and the physiological significance of ascorbate peroxidase in photosynthesizing organisms. Biosci Biotechnol Biochem. 72, 1143-1154

25 Wheeler, G. L., Jones, M. A. and Smirnoff, N. (1998) The biosynthetic pathway of vitamin $\mathrm{C}$ in higher plants. Nature. 393, 365-369

26 Foyer, C. H. and Noctor, G. (2011) Ascorbate and glutathione: the heart of the redox hub. Plant Physiol. 155, 2-18

27 Kerber, R. C. (2008) "As simple as possible, but not simpler" — The case of dehydroascorbic acid. J. Chem. Education. 85, 1237-1242

28 Deutsch, J. C. (2000) Dehydroascorbic acid. J Chromatogr. A. 881, 299-307

29 DeBolt, S. , Cook, D. R. and Ford, C. M. (2006) L-Tartaric acid synthesis from vitamin C in higher plants. Proc Natl Acad Sci USA. 103, 5608-5613 
30 Loewus, F. A. (1999) Biosynthesis and metabolism of ascorbic acid in plants and of analogs of ascorbic acid in fungi. Phytochemistry. 52, 193-210

31 DeBolt, S. , Hardie, J. , Tyerman, S. and Ford, C. M. (2004) Composition and synthesis of raphide crystals and druse crystals in berries of Vitis vinifera L. cv. Cabernet Sauvignon: ascorbic acid as precursor for both oxalic and tartaric acids as revealed by radiolabelling studies. Austral. J. Grape Wine Res. 10, 134-142

32 Franceschi, V. R. and Nakata, P. A. (2005) Calcium oxalate in plants: Formation and function. Annu. Rev. Plant Biol. 56, 41-71

33 Deutsch, J. C. (1998) Ascorbic acid oxidation by hydrogen peroxide. Analyt. Biochem. 255, 1-7

34 Isbell, H. S. and Frush, H. L. (1979) Reactions of carbohydrates with hydroperoxides. 11. Oxidation of L-ascorbic acid by hydrogen peroxide - preparation of Lthreonic acid. Carbohydr. Res. 72, 301-304

35 Green, M. A. and Fry, S. C. (2005) Vitamin C degradation in plant cells via enzymatic hydrolysis of 4-O-oxalyl-L-threonate. Nature. 433, 83-87

36 Kagawa, Y. (1962) Enzymatic studies on ascorbic acid catabolism in animals. I. Catabolism of 2,3-diketo-L-gulonic acid. J. Biochem. 51, 134-144

37 Simpson, G. L. W. and Ortwerth, B. J. (2000) The non-oxidative degradation of ascorbic acid at physiological conditions. Biochim. Biophys. Acta-Mol. Basis Disease. 1501, $12-24$

38 Fry, S. C. (2011) High-voltage paper electrophoresis (HVPE) of cell-wall building blocks and their metabolic precursors. Pp 55-80 in: The Plant Cell Wall Methods and Protocols, Edited by Z. A. Popper. Springer New York, ISBN 978-1-61779-007-2.

39 Fry, S. C. (2000) The Growing Plant Cell Wall: Chemical and Metabolic Analysis. The Blackburn Press, Caldwell, New Jersey

40 Deutsch, J. C. (1998) Spontaneous hydrolysis and dehydration of dehydroascorbic acid in aqueous solution. Analyt. Biochem. 260, 223-229

41 Cioffi, N. , Losito, I. , Terzano, R. and Zambonin, C. G. (2000) An electrospray ionization ion trap mass spectrometric (ESI-MS-MSn) study of dehydroascorbic acid hydrolysis at neutral pH. Analyst. 125, 2244-2248

42 Tolbert, B. M. and Ward, J. B. (1982) Dehydroascorbic acid. Advances in Chemistry Series. 200, 101-123

43 Green, M. A. (2004) Apoplastic ascorbate metabolism in rose cell-suspension cultures. PhD thesis, University of Edinburgh

44 Collins, P. M. and Ferrier, R. J. (1995) Monosaccharides: Their chemistry and their roles in natural products. Wiley and Sons, New York

45 Parsons, H. T. and Fry, S. C. (2010) Reactive oxygen species-induced release of intracellular ascorbate in plant cell-suspension cultures and evidence for pulsing of net release rate. New Phytol. 187, 332-342 


\section{LEGENDS TO FIGURES}

\section{Figure 1a. Proposed products formed from ascorbate under strongly oxidising conditions by $\mathrm{H}_{2} \mathrm{O}_{2}$}

(a) Proposed pathways of ascorbate catabolism. Starting material and major end-products, dark grey background; known oxidation steps, mid-grey background; newly proposed intermediates, pale grey background. Ascorbate (bottom left) is rapidly oxidised to dehydroascorbic acid (DHA), which is shown in its conventional di-oxo form (centre left) and as the hemiketal monohydrate that predominates in aqueous solution (top left). The $\mathrm{C}_{2}$ fragment derived from carbons 1 and 2 of ascorbate is indicated by a heavy $\mathrm{C}-\mathrm{C}$ bond; this fragment was radioactive in our experiments. The non-radioactive $\mathrm{C}_{4}$ fragment derived from carbons $3-6$ of ascorbate is indicated by dark grey bonds. Hypothetical intermediates are in square brackets. Thick and thin solid arrows show non-enzymatic reactions proposed to be fast and slow respectively (relative to the preceding step); dotted arrows show reactions catalysed by apoplastic enzymes; dashed arrows show the linear pathway proposed in [35]. No attempt is made to represent stereochemistry except in the two Fischer projection formulae (ascorbate and ‘dioxo' DHA).

(b) Oxalic threonic anhydride (not detected). Dotted lines show where periodate would cleave.

(c) Distinguishing cyclic oxalyl threonate from oxalic threonic anhydride. A tracer concentration of the compound tentatively identified as $\left[{ }^{14} \mathrm{C}\right] \mathrm{cOxT}$ was incubated with $\mathrm{NaIO}_{4}$ for the times indicated and then subjected to HVPE at pH 6.5; an autoradiogram is shown.

\section{Figure 2. Kinetic study of the in-vitro oxidation of $\left.{ }^{[14} \mathrm{C}\right]$ ascorbate under strongly oxidising conditions by $\mathrm{H}_{2} \mathrm{O}_{2}$}

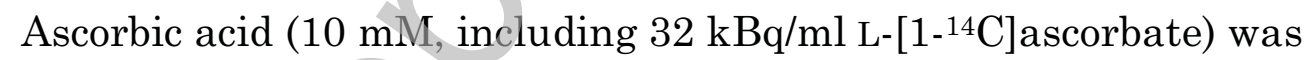
incubated at $\mathrm{pH} 6.0$ with 2 mol eq $\mathrm{H}_{2} \mathrm{O}_{2}$. After the indicated times, 5- $\mu \mathrm{l}$ aliquots were subjected to HVPE at $\mathrm{pH}$ 6.5.

(a) The autoradiogram is pictured overlying the electrophoretogram (unstained, but the internal and external marker OG spots are faintly visible; dotted circles). The experiment was carried out four times with minor variations, giving qualitatively similar results; a representative electrophoretogram is shown

(b) Radioactive zones of the electrophoretogram shown in (a) were excised and the radioactivity was quantified by scintillation counting. The radioactivity of each compound is expressed as a percentage of the total recovered at that time point. Except for ascorbate and DHA, the small amount of ${ }^{14} \mathrm{C}$ present at time 0 (dotted box in $a$ ) has been subtracted from 
the percentage. Streaks migrating between $\left[{ }^{14} \mathrm{C}\right]$ ascorbate and $\left[{ }^{14} \mathrm{C}\right] \mathrm{DHA}$, which represent immobile DHA formed from mobile ascorbate during $\mathrm{HVPE}$, have been included as $\left[{ }^{14} \mathrm{C}\right]$ ascorbate. (c) Magnification of grey box in (b). A value of $10 \%$ on the $y$-axis of (b) and (c) equates to a concentration of $1 \mathrm{mM}$ of the metabolite. (d) Relative yields of the various oxalate products.

\section{Figure 3. The in-vitro breakdown of ascorbate under moderately oxidising conditions in the absence of deliberately added metal ions}

Carrier-free L-[1-14C]ascorbic acid $(48 \mu \mathrm{M})$ was incubated in water $(\mathrm{pH} \approx$ 4.4). Reaction-mixtures were aerated by gentle shaking, during which small amounts of $\mathrm{H}_{2} \mathrm{O}_{2}$ are generated [15], but no exogenous $\mathrm{H}_{2} \mathrm{O}_{2}$ was added. Samples were analysed by HVPE at pH 6.5. An autoradiogram is shown overlying the unstained electrophoretogram. Dotted circles indicate the positions of the marker, OG, added within and between each radioactive sample.

\section{Figure 4. The in-vivo and in-vitro breakdown of ascorbate under moderately oxidising conditions in culture medium}

Carrier-free L-[1-14C] ascorbic acid $(360 \mu \mathrm{M})$ was incubated in Rosa culture medium containing: (a) no cells or cellular products; (b) living Rosa cells; (c) soluble secreted Rosa products, including native enzymes, but no cells; or (d) as (c) but enzymes had been denatured at $100^{\circ} \mathrm{C}$. In all cases, the $\mathrm{pH}$ was adjusted to 6.0 with $5 \mathrm{mM}$ Mes $\left(\mathrm{Na}^{+}\right)$. Reaction-mixtures were aerated by gentle shaking; no $\mathrm{H}_{2} \mathrm{O}_{2}$ was added. This experiment was conducted five times with qualitatively similar results; representative autoradiograms are shown. The spots are quantified in Supplementary Figure 1.

\section{Figure 5. Effect of ascorbate concentration on the in-vitro breakdown of ascorbate under moderately oxidising conditions}

L-[1-14C]Ascorbic acid (0.1 mM) was incubated in native or denatured Rosa culture-filtrates prepared as described for Fig. 4c,d. In some cases the media were supplemented with non-radioactive ascorbate to the final concentrations indicated. In all cases, the $\mathrm{pH}$ was adjusted to 6.0 with $5 \mathrm{mM}$ Mes $\left(\mathrm{Na}^{+}\right)$. Reaction-mixtures were aerated by gentle shaking; no $\mathrm{H}_{2} \mathrm{O}_{2}$ was added. The experiment was conducted twice, with qualitatively similar results; one set of electrophoretograms is shown. Incubation was for (a) $2 \mathrm{~h}$, (b) $6 \mathrm{~h}$ or (c) $24 \mathrm{~h}$. The spots are quantified in Supplementary Figure 2.

Figure 6. Proposed nature of compounds $C$ and $E$, and the origin of C by benzilic acid rearrangement of DKG 
Fischer projection formulae. The DKG is shown in its hypothetical dioxo form, although it is likely to exist in aqueous solution predominantly in a hydrated form. The original C-1 (radiolabelled in our experiments) is indicated with *; C-2 is indicated with $\dagger$. Compound $\mathbf{C}$ is expected to be a mixture of C-2 epimers (2-carboxy-L-xylonolactone and 2-carboxy-Llyxonolactone; arbitrarily shown as the $\gamma$ - rather than $\delta$-lactone form), whereas compound $\mathbf{E}$ is proposed to be the dianion of '2-carboxy-L-xylonate', which is achiral at C-2 and thus more correctly termed 2-carboxy-L-threopentonate.

\section{Figure 7. Fate of ${ }^{14} \mathrm{C}$-labelled compound $\mathrm{C}$ when incubated in Rosa cell cultures and medium}

Tracer levels of ${ }^{14} \mathrm{C}$-labelled compound $\mathbf{C}$ and/or any degradation products were subjected to HVPE at $\mathrm{pH}$ 6.5, and strips of the electrophoretogram were assayed by scintillation-counting.

(a-c) Standards: (a) ${ }^{14} \mathrm{C}$-labelled compound $\mathbf{C}$ freshly eluted from an electrophoretogram similar to that shown in Figure 5b. (b) As (a) but incubated in HOAc then neutralised with $\mathrm{NaOH}$. (c) As (a) but incubated in $\mathrm{NaOH}$ then neutralised with HOAc. $\mathbf{E}$ is the de-lactonised form of $\mathbf{C}$.

$(\mathrm{d}-\mathrm{i}){ }^{14} \mathrm{C}$-Labelled compound $\mathbf{C}$ was incubated in fresh medium (no cells or enzymes; $d, g$ ) or culture filtrate (spent medium with native secreted enzymes; e,h), or in the presence of living Rosa cells (f,i) - in each case for 2 $\mathrm{h}(\mathrm{d}, \mathrm{e}, \mathrm{f})$ or $8 \mathrm{~h}(\mathrm{~g}, \mathrm{~h}, \mathrm{i})$.

Glucose (Glc) and OG were external markers. 


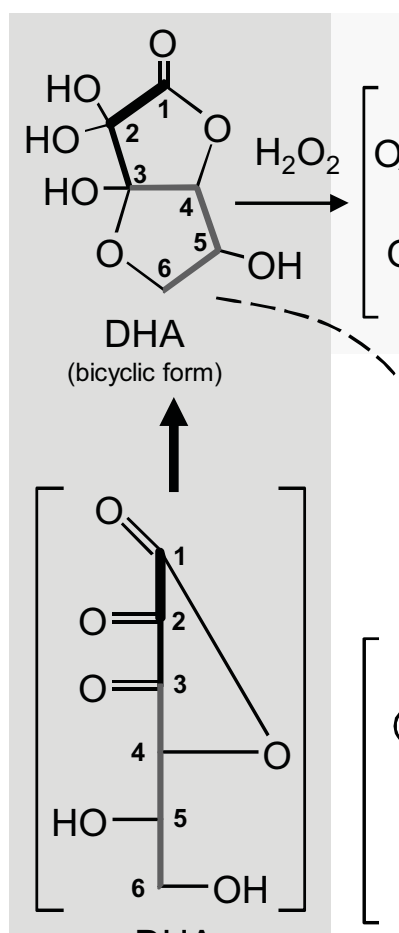

$$
\mathrm{DHA}
$$

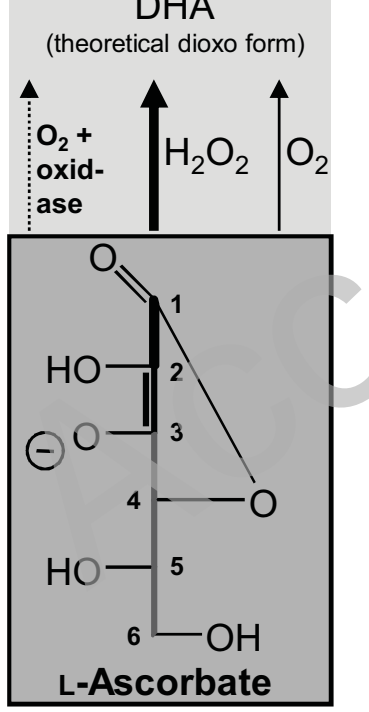<smiles>CCCOC(=O)COC(=O)COCCOC</smiles>

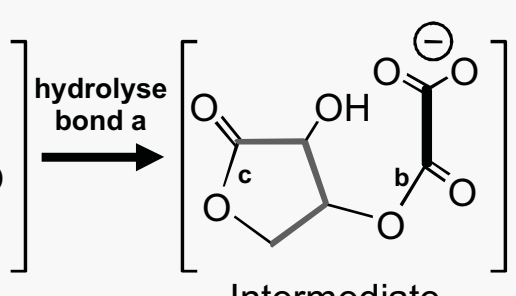

Intermediate

II
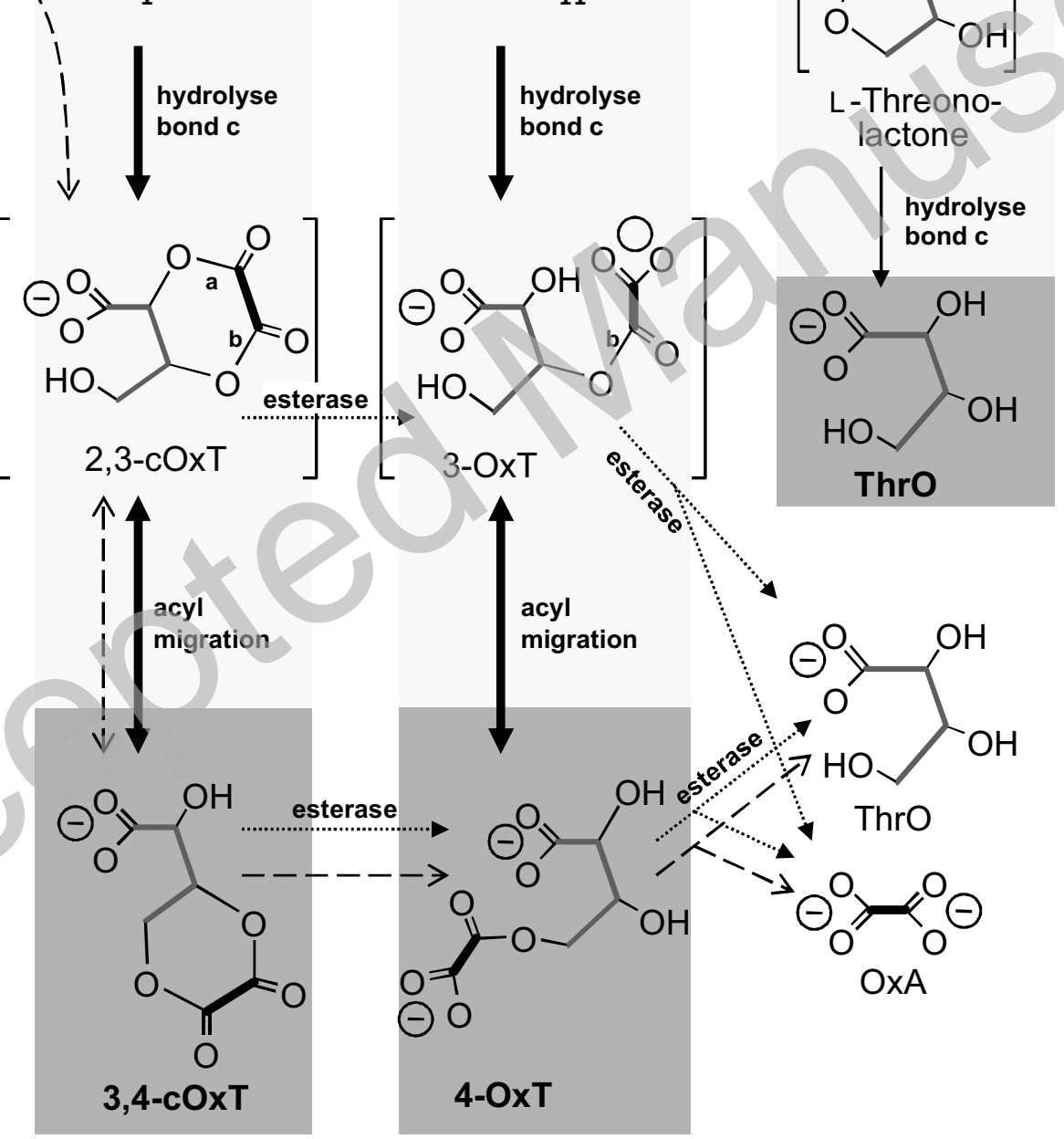

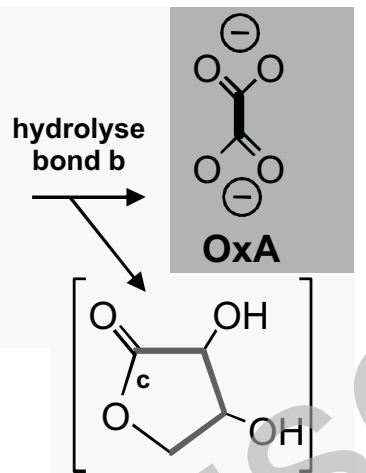

L-Threonolactone 


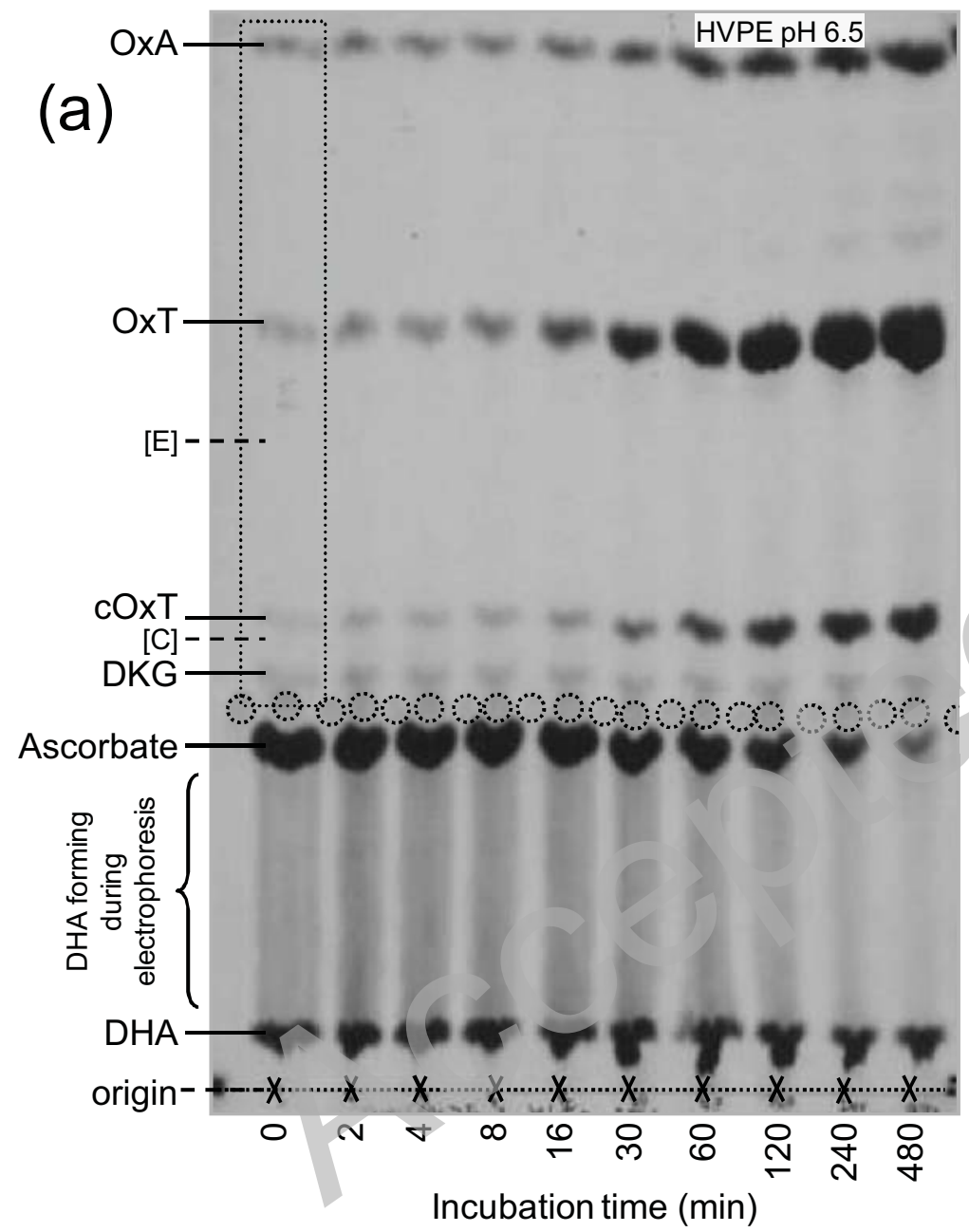

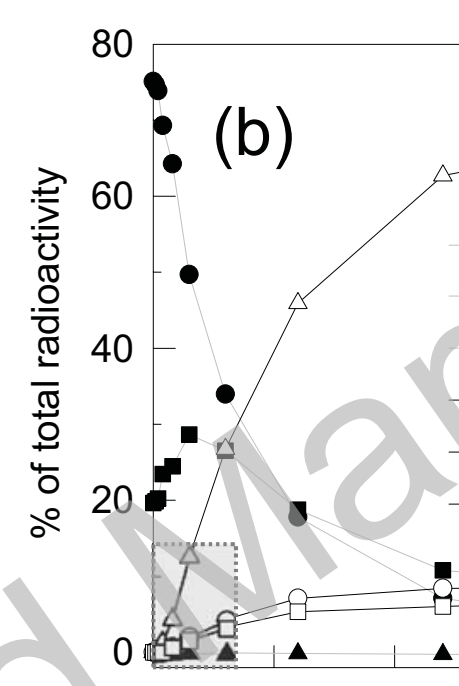

(d)

(c)

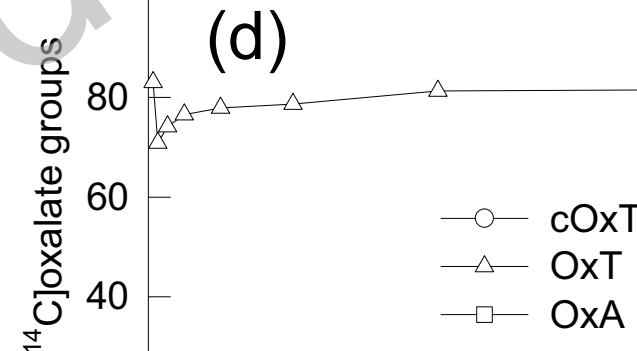

cOxT

OXT

OxA

- Ascorbate

- DHA 10

DKG

COxT

OxT

OxA

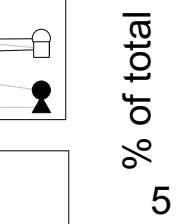

$\mathrm{OxT}$

OxA

¿० 20

200

300

400500

Incubation time (min) 


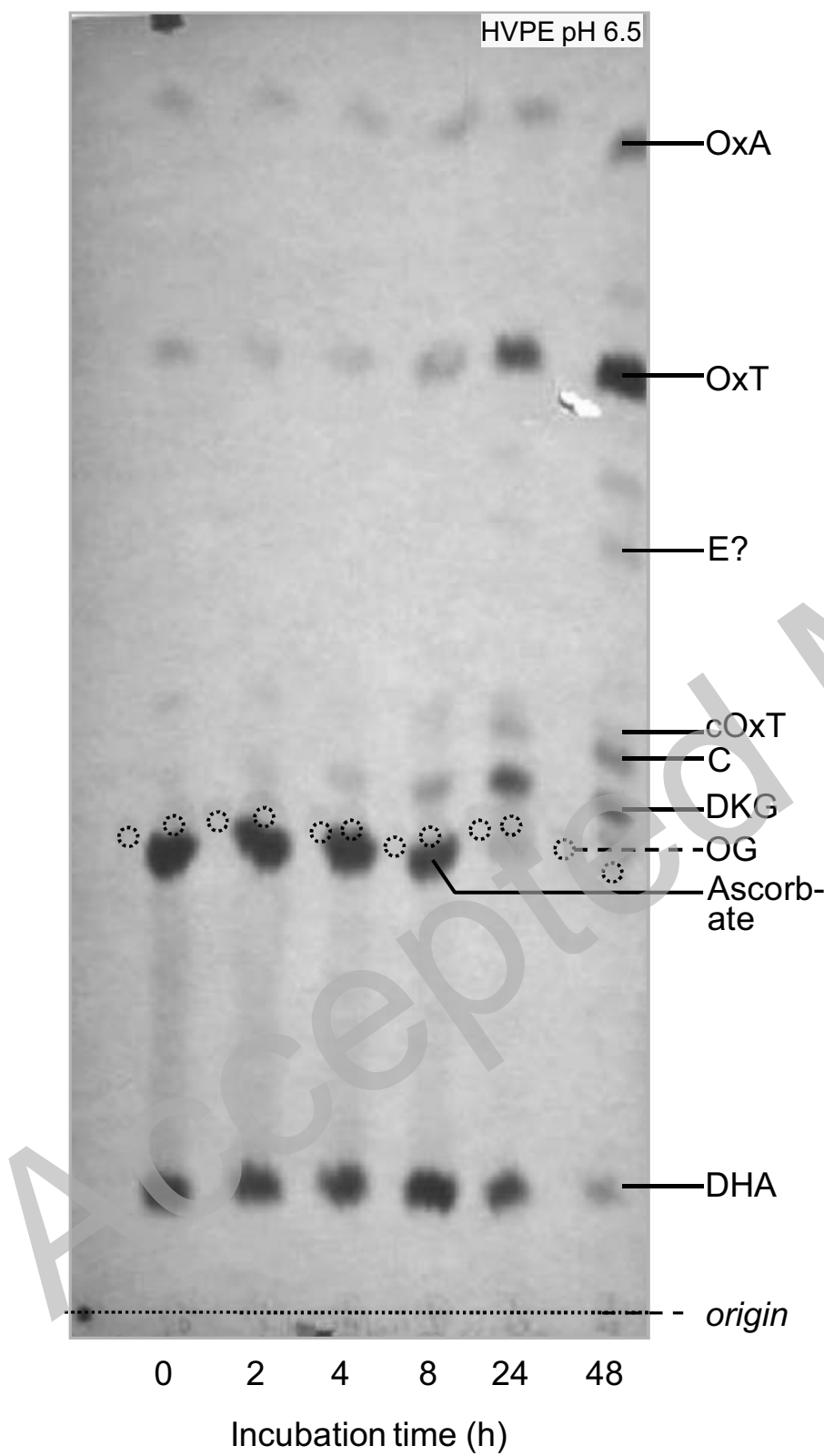

Licenced copy. Copying is not permitted, except with prior permission and as allowed by law. (C) 2011 The Authors Journal compilation @ 2011 Portland Press Limited 
(a) Fresh medium

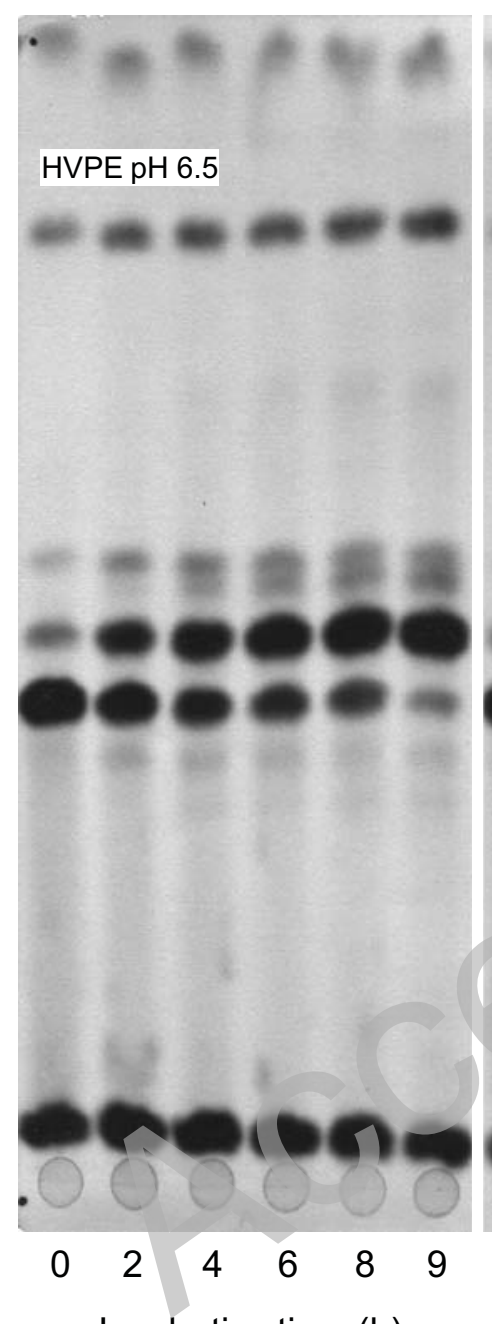

Incubation time $(\mathrm{h})$

0

Incubation time $(\mathrm{h})$ $\begin{array}{ll}\text { (b) Whole cell-culture } & \text { (c) Spent medium }\end{array}$

(d) Denatured spent medium

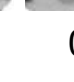

(0)
- Cmpd T
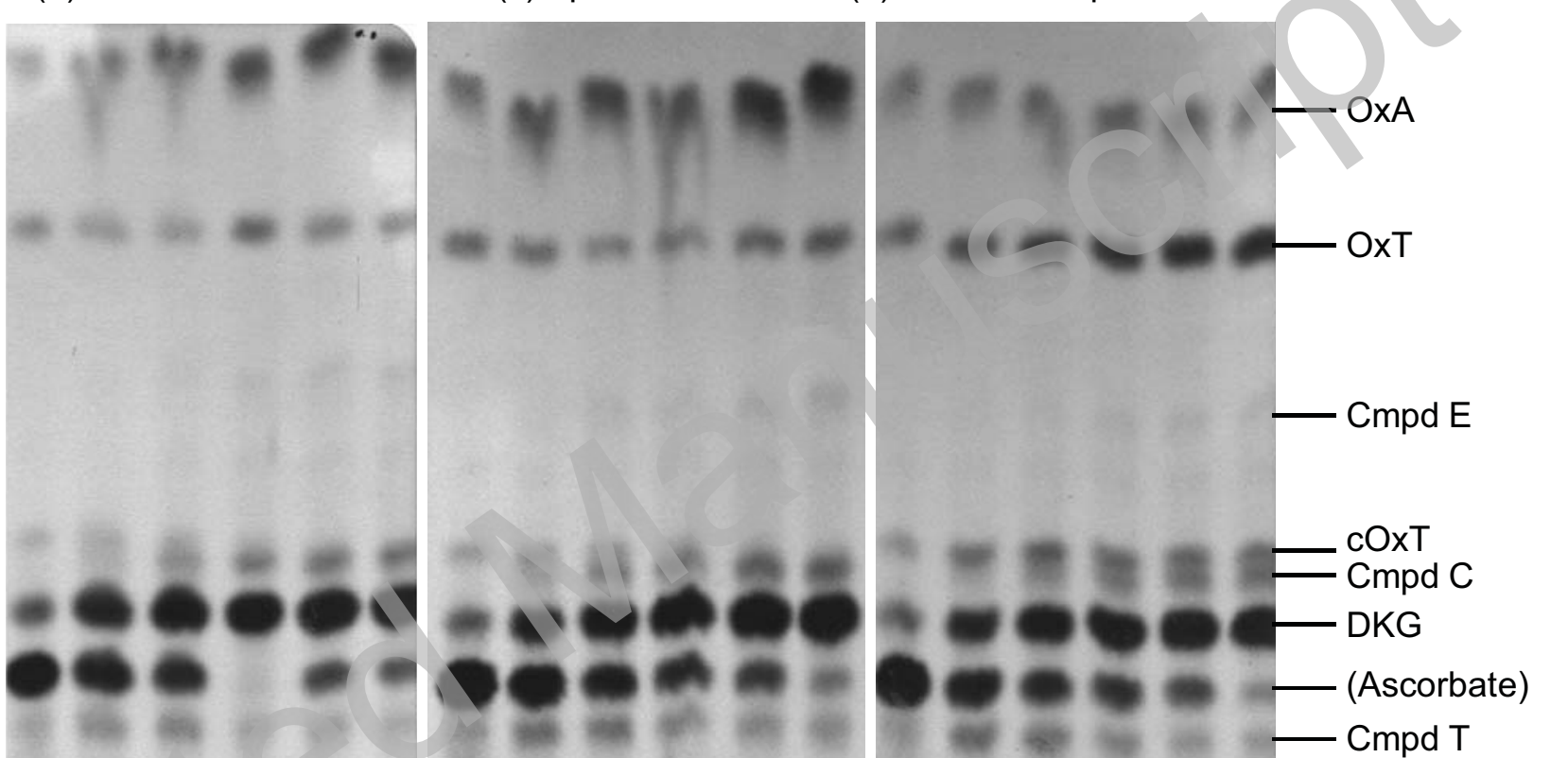

Licenced copy. Copying is not permitted, except with prior permission and as allowed by law.

(C) 2011 The Authors Journal compilation ( 2011 Portland Press Limited 
(a) $2 \mathrm{~h}$

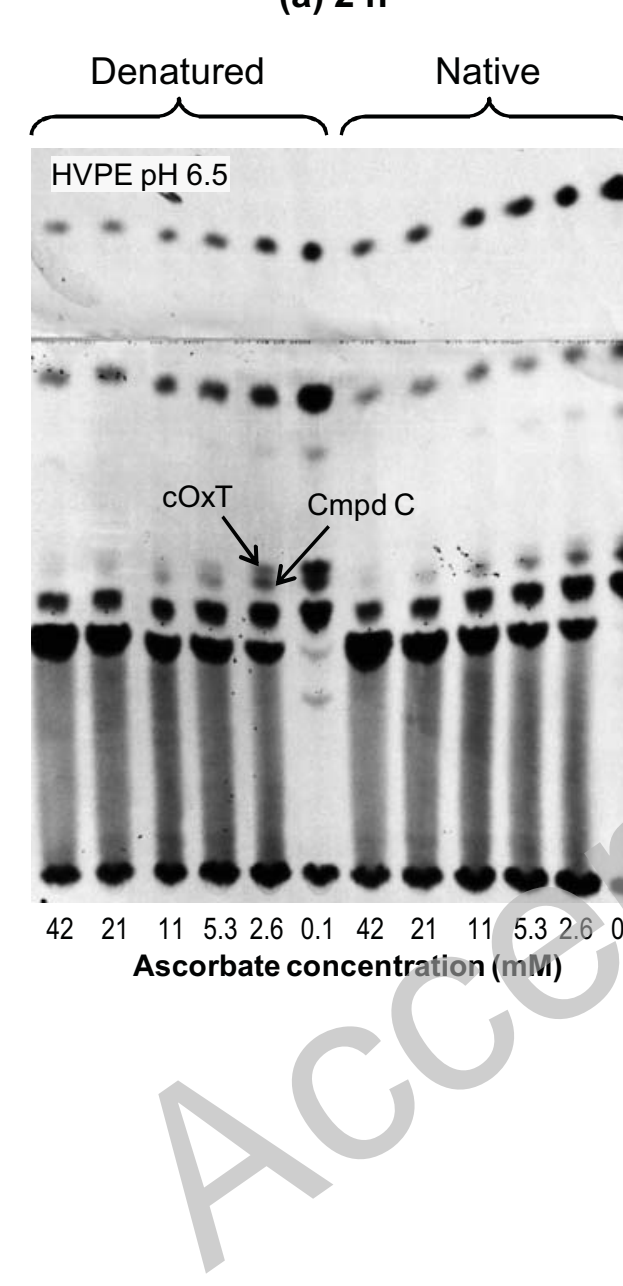

(b) $6 \mathrm{~h}$

(c) $24 \mathrm{~h}$

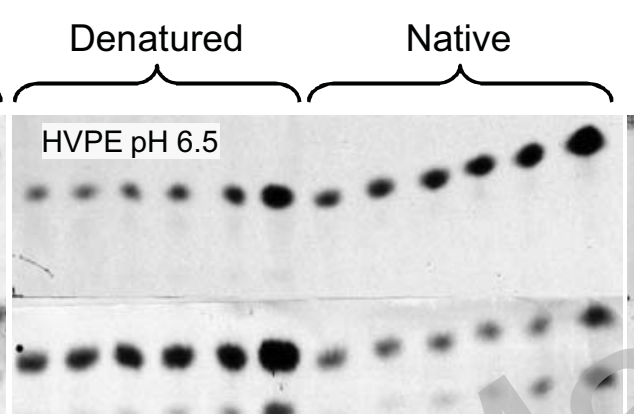

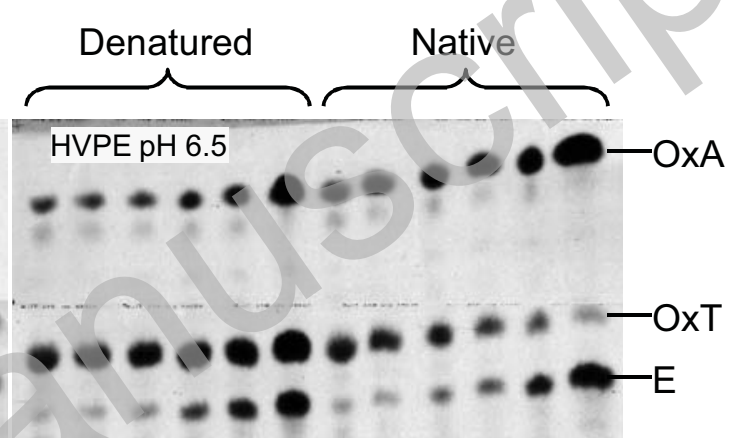
$8=2$ COxpdC<smiles>O[GeH2]</smiles>

(c) 4

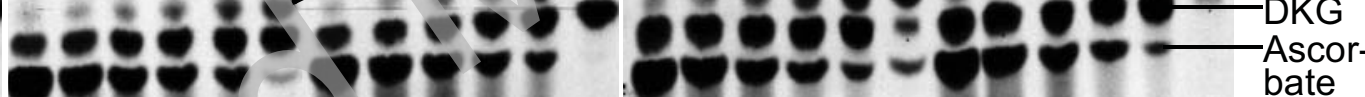
III

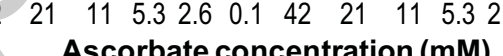
Ascorbate concentration (mM) Ascorbate concentration (mM) 
<smiles>O=C([O-])[Te]C(=O)C(=O)C(O)C(O)CO</smiles>

DKG

$$
\left(\mathrm{C}_{6} \mathrm{H}_{7} \mathrm{O}_{7}\right)^{-}
$$

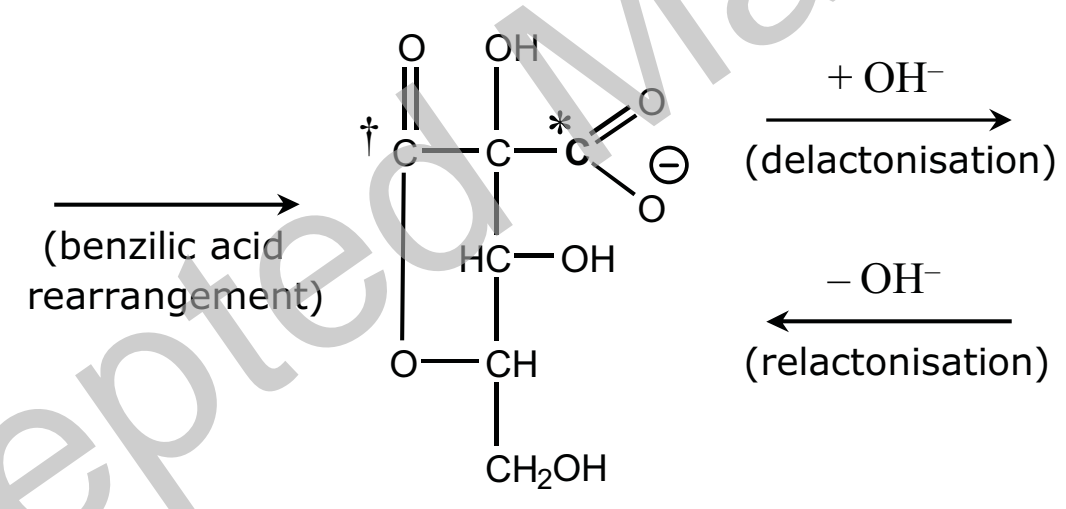

$\mathrm{C}$

$\left(\mathrm{C}_{6} \mathrm{H}_{7} \mathrm{O}_{7}\right)^{-}$<smiles>O=C([O-])C(O)(C(=O)[O-])[C@@H](O)C(O)CO</smiles>

$\mathbf{E}$

$$
\left(\mathrm{C}_{6} \mathrm{H}_{8} \mathrm{O}_{8}\right)^{2-}
$$


B) Biochemical Journal Immediate Publication. Published on 17 Aug 2011 as manuscript BJ20110939

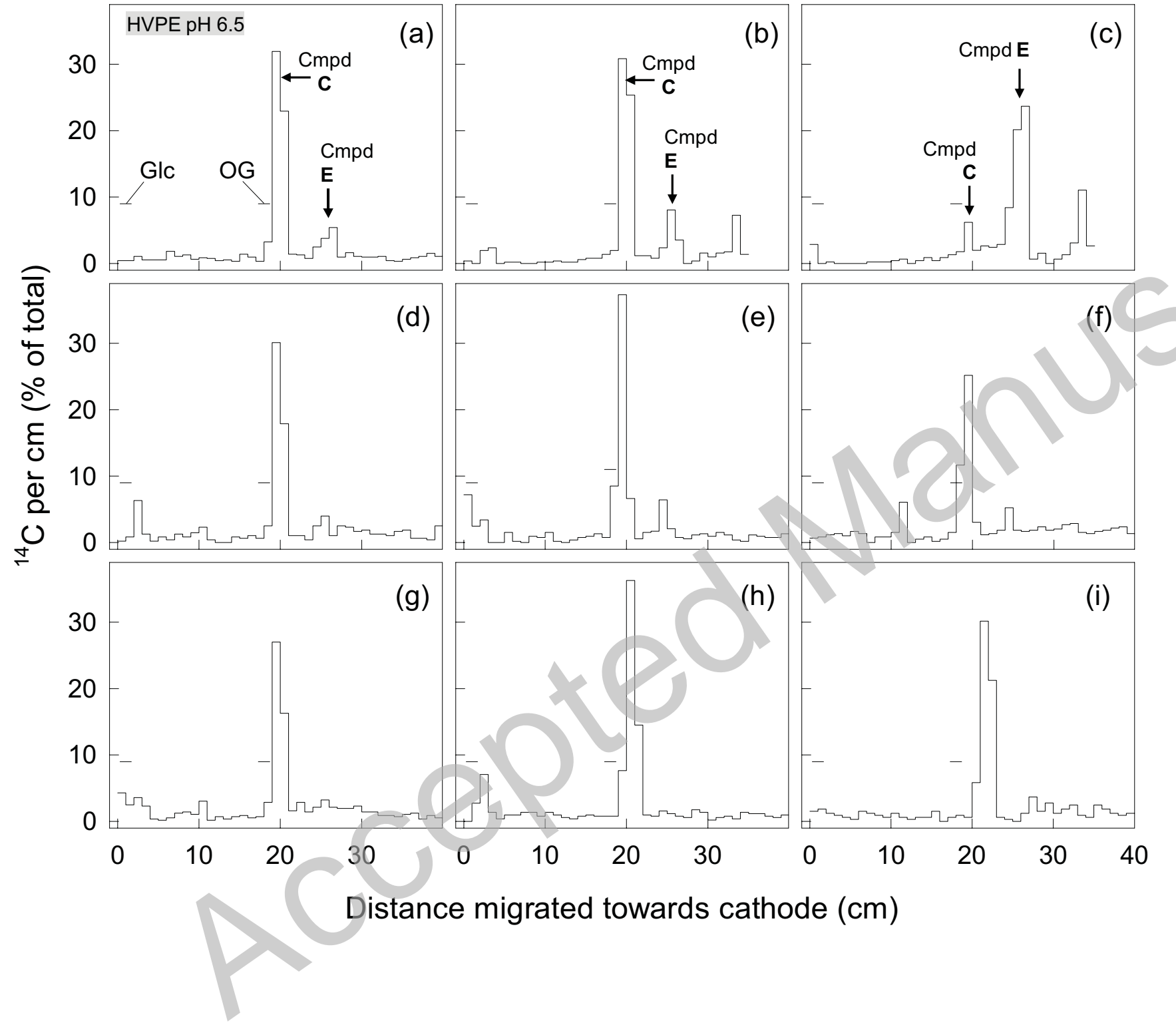

Fig. 7 